\title{
Primary renal leiomyosarcoma: A rare case report
}

\author{
Sudeshna Nandi ${ }^{1}$, Smritiparna Das ${ }^{1}$, Chhanda Das ${ }^{2}$, Madhumita Mukhopadhyay ${ }^{3}$ \\ From ${ }^{1}$ Post Graduate, ${ }^{2}$ Assistant Professor, ${ }^{3}$ Professor, Department of Pathology, Institute of Post Graduate Medical Education and Research and Seth \\ Sukhlal Karnani Memorial Hospital, Kolkata, West Bengal, India
}

\begin{abstract}
Leiomyosarcoma of the kidney is a rare type of adult renal sarcoma. Here, we presented a case of a 68-year-old female who had a past history of bilateral renal calculi 3 years back with hydronephrotic changes, now presented to the OPD with complaints of abdominal pain for the past few months. On further evaluation, a heterogeneously enhancing necrotic mass was identified in the right kidney measuring $7.5 \mathrm{~cm}$ in the greatest dimension. A right radical nephrectomy with left Double J stenting was done. From histopathological and immunohistochemical staining, it was diagnosed as leiomyosarcoma.
\end{abstract}

Key words: Renal calculi, Renal, Sarcoma

$\mathrm{R}$ enal leiomyosarcomas are the most common type of sarcomas, accounting for $50-60 \%$ of all the sarcomas arising in the kidney [1]. It accounts for $<1 \%$ of all renal malignancies accounting for only $0.12 \%$ of renal malignancies $[2,3]$. There are no known predisposing factors. It is also known to preferentially affect females in their 60's [4].

Here, we report a rare case of renal leiomyosarcoma in a 68 -year-old female and also reviewed the relevant literature below.

\section{CASE REPORT}

A 68-year-old lady presented to the OPD with complaints of mild to moderate abdominal pain which was fluctuating in nature for the past 6 months. The patient also complained of anorexia and significant weight loss for the past 6 months.

Her physical examination showed an easily ballotable, non-tender mass, lobular in shape, and firm in consistency. 3 years earlier, she presented with bilateral renal calculi with hydronephrotic changes which passed spontaneously in urine without any intervention, with medication.

Her routine hematological examination at present showed anemia with hemoglobin of $9 \mathrm{~g} \%$. The biochemical investigations were all within normal limits. Urinalysis showed mild hematuria with 4-6RBCs/hpf. Urine culture turned out to be negative but urine cytology revealed a few atypical cells suspicious for malignancy. No other hematological or biochemical abnormality was detected

\section{Access this article online}

Received - 31 October 2021

Initial Review - 12 November 2021

Accepted - 20 November 2021

DOI: $10.32677 /$ ijcr.v7i11.3156 except anemia. Occult blood in stool and urine were negative. On further evaluation of the patient, a heterogeneously enhancing necrotic mass was identified in the right kidney measuring $7.5 \mathrm{~cm}$ in greatest dimension on computed tomography scan (Fig. 1).

Subsequently, the right nephrectomy was performed with left Double J stenting. Gross examination revealed a well-defined tumor mass measuring $8 \mathrm{~cm} \times 8 \mathrm{~cm} \times 7 \mathrm{~cm}$, with cut surface showing areas whitish whorling with focal areas of necrosis (Fig. 2).

Microscopic examination of the tumor masses revealed a malignant neoplasm composed of spindle cells arranged predominantly in fascicles and somewhere in plexiform pattern, with marked nuclear pleomorphism and prominent nucleoli with acidophilic cytoplasm (Fig. 3). Atypical mitotic activity was present. Sections from the adjacent renal parenchyma did not reveal any neoplastic component apart from changes of chronic tubulointerstitial nephritis. Major vessels showed no sign of tumor dissemination. An extensive regrossing was performed to look for any epithelial components in the tumor mass but revealed none by microscopy. Immunohistochemically, the neoplastic cells showed membrane positivity for desmin (Fig. 4). Hence, from the histomorphology and immunohistochemistry, it was diagnosed as a case of primary renal leiomyosarcoma.

\section{DISCUSSION}

Leiomyosarcoma is a malignant tumor of smooth muscle component of soft tissue. It is essentially a tumor of adults and the elderly population, but some cases have also been reported in children [5]. Apart from the uterus, soft tissue leiomyosarcoma

Correspondence to: Dr. Chhanda Das, 31 Eastern Park, Santoshpur, Kolkata - 700075, West Bengal, India. E-mail: chhhdas@gmail.com

(C) 2021 Creative Commons Attribution-NonCommercial 4.0 International License (CC BY-NC-ND 4.0). 


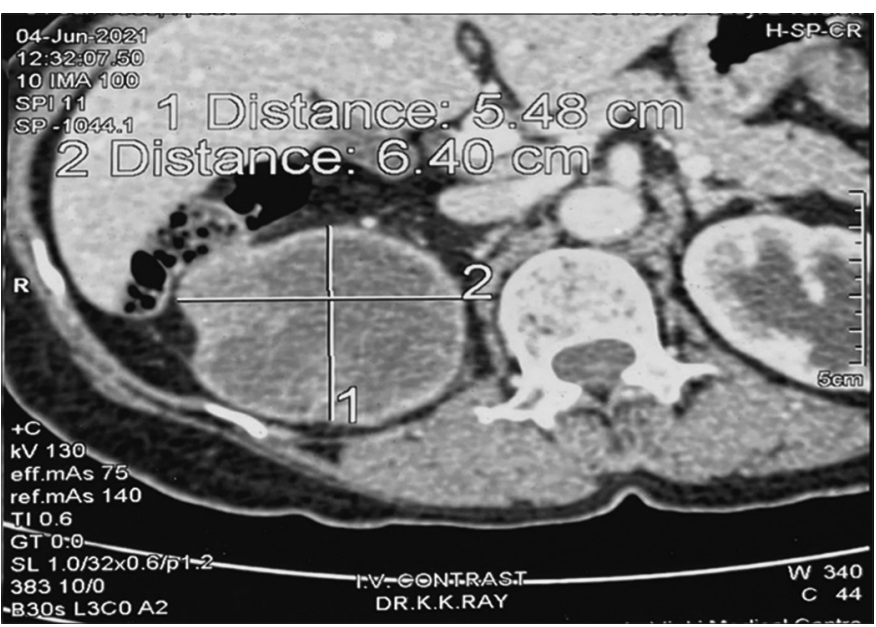

Figure 1: Computed tomography scan image showing heterogeneously enhancing necrotic mass involving whole of the right kidney

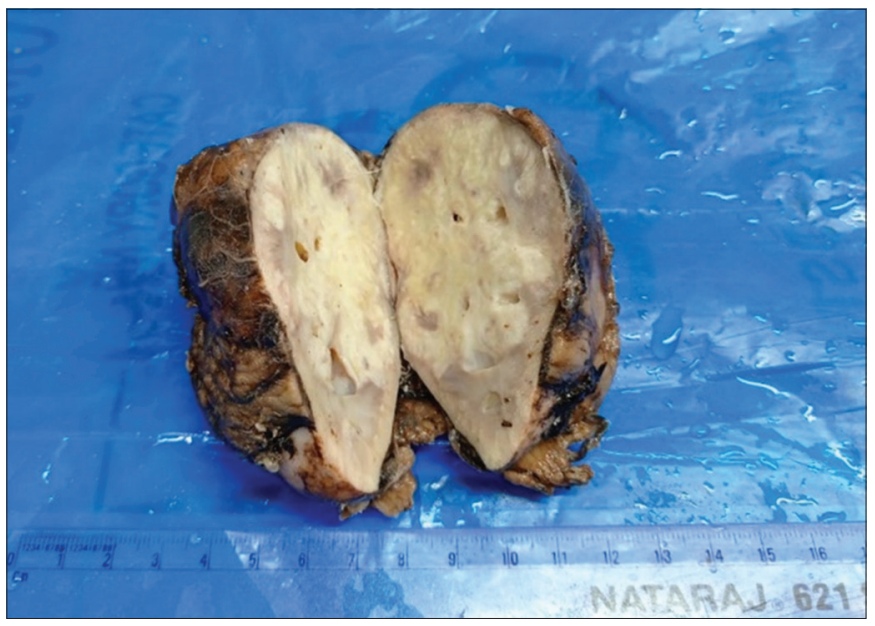

Figure 2: Gross picture of renal leiomyosarcoma

commonly occurs in the retroperitoneum and blood vessels. Leiomyosarcomas of non-peritoneal soft tissue sites usually involves the lower extremity and can also occur in the head and neck region [6]. They are most commonly found in the uterus, stomach, small intestine, and retroperitoneum [7]. Renal leiomyosarcomas are believed to originate from the renal capsule or the smooth muscle fibers in the renal pelvis or from the renal vessels [4].

The incidence of the primary renal leiomyosarcoma increases with the age of the patient. This tumor was found to be more common in females than in males and more common in the right kidney than in the left kidney according to a study conducted by Beardo et al. [8] Farrow et al. found a preponderance of renal leiomyosarcomas in females and more frequent after the fifth decade of life [9]. Furthermore, in a study performed by Dhamne et al., it was found that the renal leiomyosarcomas have a female preponderance, with females being twice more commonly affected by renal leiomyosarcomas than males with most of the patients presenting in their fourth-sixth decades [10]. Renal leiomyosarcomas are found to be typically occurring between the fourth and eighth decades of life, more commonly found among women and arising from the right kidney as found

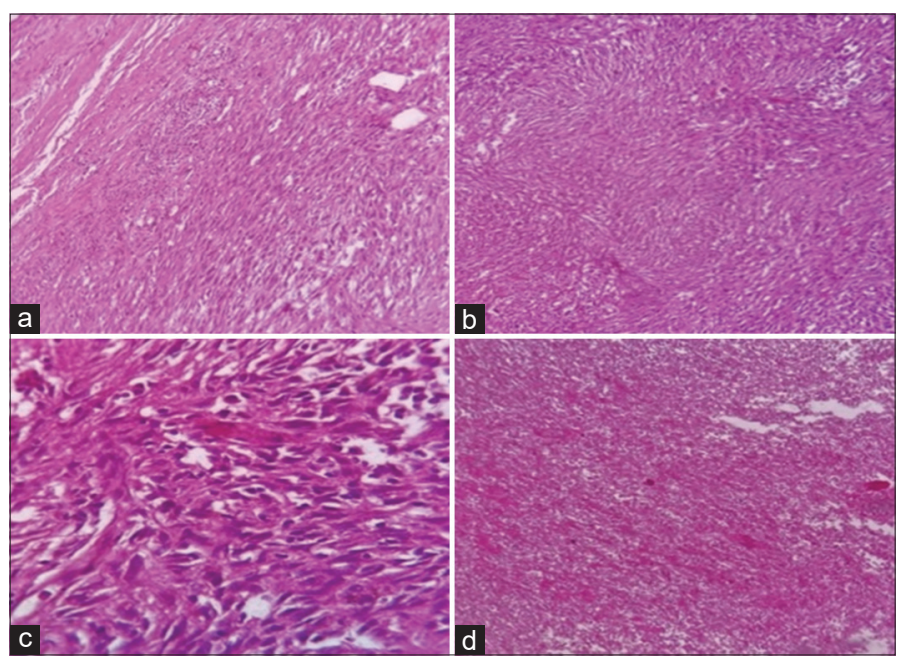

Figure 3: (a) Picture showing tumor portion with adjacent renal tubules $\times 100$ (H and E); (b) Picture showing tumor $\times 100$ (H and E); (c) Tumor composed of spindle cells with eosinophilic cytoplasm. Many atypical mitotic figures can be identified. $\times 400(\mathrm{H}$ and $\mathrm{E}$ ); (d) Areas of extensive necrosis adjacent to tumor cells $\times 100$ (H and E)

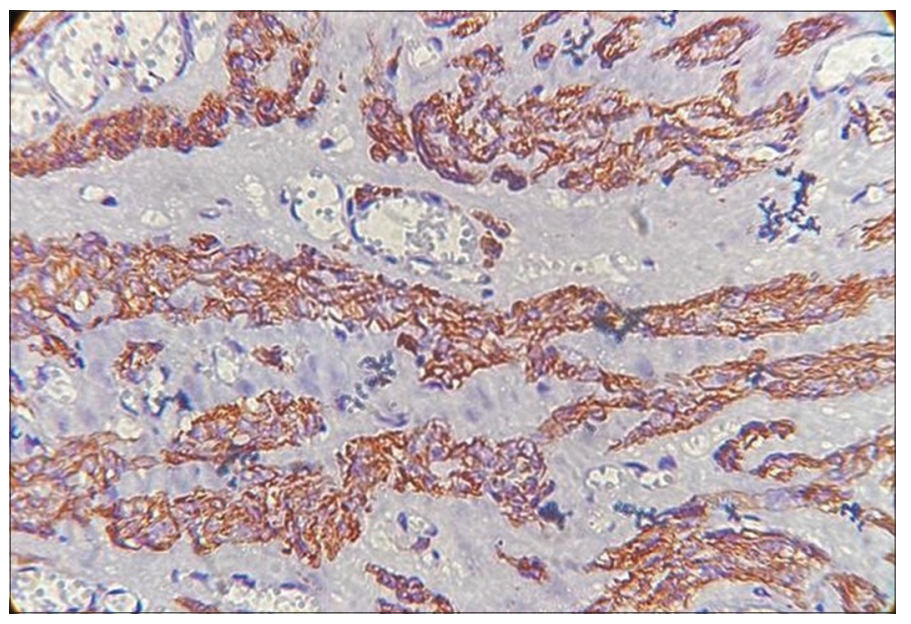

Figure 4: Membrane expression of Desmin $\times 400$

by Miller et al. [11] Polianko et al. concluded in their study that renal leiomyosarcomas can occur on both the left and right sides equally and can also occurs bilaterally; however, the etiology was not known [12]. The reason behind female preponderance is unknown, but a study performed by Brown et al. suggested that some malignancies are associated with genes located on the $\mathrm{X}$ chromosome which escape X chromosome inactivation [13].

Clinical features of renal leiomyosarcomas are very similar to more common renal malignancies which consist of hematuria, flank pain, progressive weight loss, and an abdominal mass lesion. As the tumor increases in size, it produces symptoms such as lumbar pain and hematuria and a palpable mass [8].

Grossly, the tumors look like leiomyomas with a well-circumscribed margin and whorled appearance on the cut section. However, the malignant counterpart appears fleshy and has areas of hemorrhage, necrosis, and degenerative changes [9]. Gross examination of the tumor shows evident trabeculations and whorling pattern; the combined light microscopy with immunohistochemistry gives the definitive diagnosis of 
leiomyosarcoma. The sarcomatoid variant of renal cell carcinoma is the chief differential diagnosis of renal leiomyosarcoma. Other differential diagnoses which can be confused with leiomyosarcoma are the epithelioid variant of renal angiomyolipoma and renal synovial sarcoma. Hence, immunohistochemistry is an important investigation for the evaluation of such tumors to avoid the wrong diagnosis [11].

On microscopy, renal leiomyosarcomas show smooth muscle cells arranged in a fascicular pattern, with individual cells showing marked nuclear atypia and prominent mitotic figures. They show a positive expression of smooth muscle markers such as smooth muscle actin, calponin, desmin, and h-caldesmon and are negative for cytokeratin, S-100 protein, and HMB45 on immunohistochemistry. The sarcomatoid variant of renal cell carcinoma reveals foci of typical renal cell carcinoma with cytokeratin positivity while the smooth muscle markers are negative. Epithelioid angiomyolipoma shows positivity for both smooth muscle markers and melanocytic markers, while renal synovial sarcomas show positivity for smooth muscle markers and $\mathrm{Bcl} 2$ [11,12].

Renal leiomyosarcomas show aggressive behavior due to rapid growth rate, frequent distant metastases, and high recurrence rates. Distant metastases have been reported to the lungs, liver, and gastrointestinal tract. Radical nephrectomy is the treatment of choice for primary renal leiomyosarcoma $[10,11]$. Because of the limited data, the role of adjuvant chemoradiotherapy is still in doubt [11]. The mean survival rate of renal leiomyosarcomas ranges from 6 months to 2 years after the diagnosis is made [2,14]. Kwon et al. reported a case of renal leiomyosarcoma in a 46-year-old Caucasian male [15]. Renal leiomyosarcomas usually show aggressive behavior, and the prognosis appears to be poor with a median survival between 17.9 and 25 months [16]. Total surgical resection is the major prognostic factor [17]. Radical nephrectomies, size of the tumor $<5 \mathrm{~cm}$, low histologic grade of the tumor, and negative lymph nodal status are all associated with a better prognosis in patients with leiomyosarcomas [15].

\section{CONCLUSION}

We presented a rare case of renal leiomyosarcoma in a 68-year-old female. A nodular mass with a whorled cut surface resembling a leiomyoma raises a suspicion of a smooth muscle tumor in the kidney. This tumor was sampled extensively. Histopathological examination alone is insufficient to give a definite diagnosis. Immunohistochemistry is essential to prove the smooth muscle cell origin of the tumor and also for differentiating it from the sarcomatoid variant of renal cell carcinoma.

\section{REFERENCES}

1. Chung YG, Kang SC, Yoon SM, Han JY, Seong DH. Leiomyosarcoma arising from a blind end of bifid renal pelvis. Yonsei Med J 2007;48:557-60.

2. Yodonawa S, Ogawa I, Yoshida S, Ilo H, Kato A, Kubokawa E, et al. Gastric metastasis from a primary renal leiomyosarcoma. Case Rep Gastroenterol 2012;6:314-8.

3. Dhawan S, Chopra P, Dhawan S. Primary renal leiomyosarcoma: A diagnostic challenge. Urol Ann 2012;4:48-50.

4. Niceta P, Lavengood RW Jr., Fernandes M, Tozzo PJ. Leiomyosarcoma of kidney. Review of the literature. Urology 1974;3:270-7.

5. Brandjord RM, Reaume CE, Wesley RK. Leiomyosarcoma of the floor of the mouth: Review of literature and report of case. J Oral Surg 1977;35:590-4.

6. Angel CA, Gant LL, Parham DM, Rao BN, Douglass EC, Lobe T. Leiomyosarcomas in children: Clinical and pathologic characteristics. Pediatr Surg Int 1992; 7:116-20.

7. Weiss SN. Smooth muscle tumors of soft tissue. Adv Anat Pathol 2002;9:351-9.

8. Beardo P, José Ledo M, Jose Luis RC. Renal leiomyosarcoma. Rare Tumors 2013;5:e42.

9. Farrow GM, Harrison EG, Remine WH. Sarcomas and sarcomatoid and mixed malignant tumors of the kidney in adults. Cancer 1968;22:545-50.

10. Dhamne SA, Gadgil NM, Padmanabhan A. Leiomyosarcoma of the renal pelvis. Indian J Pathol Microbiol 2009;52:549-51.

11. Miller JS, Zhou M, Brimo F, Guo CC, Epstein JI. Primary leiomyosarcoma of the kidney: A clinicopathologic study of 27 cases. Am J Surg Pathol 2010;34:238-42.

12. Polianko NI. Leiomyosarcoma of both kidneys. Arkh Patol 1986;48:70-2.

13. Brown CJ, Greally JM. A stain upon the silence: Genes escaping X inactivation. Trends Genet 2003;19:432-8.

14. Deyrup AT, Montgomery E, Fisher C. Leiomyosarcoma of the kidney: A clinicopathological study. Am J Surg Pathol 2004;28:178-82.

15. Kwon YS, Salmasi Y, Han CS, Hon JD, Singer EA. Renal leiomyosarcoma: Case report and review of the literature. World J Nephrol Urol 2015;4:213-7.

16. Vogelzang NJ, Fremgen AM, Guinan PD, Chmiel JS, Sylvester JL, Sener SF. Primary renal sarcoma in adults: A natural history and management study by the American cancer society, Illinois division. Cancer 1993;71:804-10.

17. Sobti P, Rakheja G, Mittal A, Khurana N, Aggarwal SK. Isolated renal mucormycosis in a pediatric patient. J Case Rep 2013;3:390-2.

Funding: None; Conflicts of interest: None Stated.

How to cite this article: Nandi S, Das S, Das C, Mukhopadhyay M. Primary renal leiomyosarcoma: A rare case report. Indian J Case Reports. 2021;7(11):503-505. 